\title{
Ngn3 expression during postnatal in vitro beta cell neogenesis induced by the JAK/STAT pathway
}

\author{
L Baeyens ${ }^{1,2}$, S. Bonné ${ }^{1}$, MS German ${ }^{3}$, P Ravassard ${ }^{4}$, \\ H Heimberg ${ }^{1}$ and L Bouwens ${ }^{*, 1,2}$ \\ 1 Diabetes Research Center, Vrije Universiteit Brussel (Free University of \\ Brussels), Brussels 1090, Belgium \\ 2 Cell Differentiation Unit, Vrije Universiteit Brussel (Free University of Brussels), \\ Brussels 1090, Belgium \\ ${ }^{3}$ Hormone Research Institute and Department of Medicine, University of \\ California San Francisco, San Francisco, CA 94143, USA \\ ${ }^{4}$ CNRS, Hôpital Pitié Salpêtrière,Paris, France \\ * Corresponding author: L Bouwens, Vrije Universiteit Brussel, Laarbeeklaan \\ 103, B-1090 Brussels, Belgium. Tel.: + 322 4774457; Fax: + 322 4774405; \\ E-mail: lucbo@vub.ac.be
}

Received 10.8.05; revised 29.12.05; accepted 16.1.06; published online 03.3.06 Edited by V De Laurenzi

\section{Abstract \\ The basic helix-loop-helix protein Neurogenin3 specifies precursor cells of the endocrine pancreas during embryonic development, and is thought to be absent postnatally. We have studied Ngn3 expression during in vitro generation of beta-cells from adult rat exocrine pancreas tissue treated with epidermal growth factor and leukaemia inhibitory factor. This treatment induced a transient expression of both $\mathrm{Ngn} 3$ and its upstream activator hepatocyte nuclear factor 6 . Inhibition of EGF and LIF signalling by pharmacological antagonists of the JAK2/STAT3 pathway, or knockdown of Ngn3 by RNA interference prevented the generation of new insulin-positive cells. This study demonstrates that in vitro growth factor stimulation can induce recapitulation of an embryonic endocrine differentiation pathway in adult dedifferentiated exocrine cells. This could prove to be important for under- standing the mechanism of beta-cell regeneration and for therapeutic ex vivo neogenesis of beta cells. \\ Cell Death and Differentiation (2006) 13, 1892-1899. \\ doi:10.1038/sj.cdd.4401883; published online 3 March 2006}

Keywords: neurogenin3; transdifferentiation; beta cell; pancreas; diabetes

\begin{abstract}
Abbreviations: CK20, cytokeratin 20; EGF, epidermal growth factor; eGFP, enhanced green fluorescent protein; Hnf6, hepatocyte nuclear factor 6; JAK2, Janus kinase 2; LIF, leukaemia inhibitory factor; Ngn3, neurogenin 3; Pdx1, pancreatic and duodenal homeobox 1; STAT3, signal transducer and activator of transcription 3
\end{abstract}

\section{Introduction}

There is currently a lot of interest in the development of a treatment for diabetes that is based on beta-cell replacement or regeneration. Beta-cells could be (re-)generated by stimulation of beta-cell replication and/or (trans-)differentiation of stem/progenitor cells. It has been demonstrated that, during adult life, beta-cell maintenance and compensatory growth in mice results primarily from proliferation of the pre-existing beta cells. ${ }^{1}$ However, numerous reports of alternative sources of beta-cell 'neogenesis' in response to severe tissue injury have been described. ${ }^{2-6}$ The pancreas is composed of exocrine tissue, comprising acinar and duct cells, and of endocrine tissue that contains beta-, alpha-, delta- and pancreatic polypeptide cells. A possible source of progenitor cells is the acinar cell population that is the most abundant in adult pancreas and is known to retain a remarkable plasticity both in vivo and in vitro. ${ }^{7-9}$ Isolated acinar cells can undergo dedifferentiation in vitro whereby they lose their zymogen granules and gain a duct-like phenotype including expression of the duct cell marker cytokeratin20.,10 External stimuli can induce a phenotypical switch in these cells towards a hepatocyte-like phenotype. ${ }^{7}$ We have recently developed a model for in vitro beta-cell neogenesis based upon growth factor stimulation of dedifferentiated acinar pancreatic cells. ${ }^{11}$ The molecular regulation of this transdifferentiation from acinar to beta cells is unknown at present. Although it is known that during pancreatic regeneration the exocrine population can dedifferentiate towards an embryonic-like state in vivo, ${ }^{12}$ in vitro recapitulation of the pro-endocrine developmental pathway has not yet been described at the molecular level. During embryonic development both the exocrine and endocrine cell populations differentiate from a common endodermal progenitor ${ }^{13,14}$ under control of a hierarchy of transcription factors. During pancreatic specification it is well documented that the transient expression of the basic helixloop-helix transcription factor neurogenin3 (Ngn3) defines the endocrine precursor pool within the embryonic endoderm. ${ }^{13}$ Lineage tracing studies have demonstrated that Ngn3expressing cells exclusively give rise to endocrine cells ${ }^{15}$ and targeted deletion of Ngn3 results in agenesis of all islet cells. ${ }^{16}$ Additionally, ectopic expression of Ngn3 predestines embryonic endoderm to an endocrine fate. ${ }^{13,17-19}$ In adult pancreas, Ngn3 is no longer expressed, or it is expressed at very low level. ${ }^{15}$ It is not known whether re-expression of Ngn3 occurs in adult cells during regeneration. The exact nature of the upstream activator of $\mathrm{Ngn} 3$ remains elusive, although $\mathrm{Hnf} 6$ has been proposed as a possible regulator of Ngn3. ${ }^{20}$

Our present study shows that a transient reactivation of the embryonic transcription factor Ngn3 plays an important role in beta-cell neogenesis from adult acinar tissue. The expression of Ngn3 can be induced in the acinar cell population and is controlled by the JAK/STAT pathway.

\section{Results}

\section{Culture model}

Rat exocrine acini were isolated and precultured as described previously. ${ }^{8,11}$ These cells lose their exocrine zymogen 
granules and more than $90 \%$ of them are immunoreactive for the ductal marker CK20, most of the remaining cells being fibroblasts. Owing to pretreatment with alloxan, a well-known beta-cell toxin, the amount of insulin-immunoreactive beta cells present in these preparations is reduced to $0.3 \pm 0.1 \%$. Cells were allowed to form adherent monolayer cultures and were treated with either control medium or medium supplemented with the growth factors EGF and LIF to induce betacell neogenesis during a period of 3 days as described. ${ }^{11}$

\section{Ngn3 expression profile}

In this model of beta-cell neogenesis, a gene profile analysis was performed using PCR, as to examine the effects of growth factors EGF and LIF on transdifferentiation of acinar exocrine cells to beta cells. It was therefore assessed whether the re-expression of the pro-endocrine pancreatic transcription factor Ngn3 contributes to the increase in number of beta cells seen in the growth factor-treated conditions. When the gene expression profile was analyzed by RT-PCR, Ngn3 mRNA was readily detectable in the growth factor-treated cultures, but was not detectable in normal rat pancreas, purified rat islets or exocrine cell aggregates with 30 cycles of PCR. However, low Ngn3 mRNA expression was detected in alloxan-treated cells cultured in control medium (Figure 1a). mRNA for the beta-cell markers Pdx1 and insulin was only present following addition of EGF and LIF (not shown). Analysis using conventional PCR revealed a transient upregulation of $\mathrm{Ngn} 3$ (Figure $1 \mathrm{~b}$ ). Before and $24 \mathrm{~h}$ after the addition of growth factors, both $\mathrm{Pdx} 1$ and insulin were undetectable while the expression of these beta-cell markers appeared within $48 \mathrm{~h}$ and became maximally expressed by $72 \mathrm{~h}$ following stimulation (Figure $1 \mathrm{~b}$ ). The level of Ngn3 transcripts was quantified by real-time RT-PCR and found 4.7-fold $(n=3 ; P<0.05)$ induced in alloxan-treated pancreatic exocrine cell culture as compared to pancreas. Ngn3 mRNA levels increased as early as $24 \mathrm{~h}$ after initiation of growth factor treatment (Figure 1c). As compared to alloxan-treated cell culture after $\mathrm{Oh}$ of treatment, addition of EGF and LIF induced Ngn3 transcript levels, respectively, 2.3-, 10.5- and 4.1 -fold $(n=3, P<0.05)$ after 24,48 , and $72 \mathrm{~h}$ of culture (Figure 2a). Ngn3 protein expression was analyzed immunocytochemically on the monolayer cultures at $\mathrm{O} \mathrm{h}$ (control) and $24 \mathrm{~h}, 48 \mathrm{~h}, 72 \mathrm{~h}$, and $96 \mathrm{~h}$ after growth factor stimulation (Figure 2b). We could not detect Ngn3 immunoreactivity in control cultures without growth factors, at any time point and regardless of alloxan pretreatment. In growth factor-treated conditions, however, intense Ngn3 immunoreactivity was detected in part of the cells $(4.77 \pm 2.27 \% ; n=3)$ as early as $24 \mathrm{~h}$ after addition of growth factors (Figure $2 \mathrm{~b}$ ). At this stage, Ngn3 was predominantly detected in the cytoplasm (Figure 2c), although few cells expressed nuclear Ngn3. When attempting to phenotypically identify these cells, we observed that about $5 \%$ of the Ngn3-positive cells coexpressed the ductal marker cytokeratin20 and about $10 \%$ coexpressed the epithelial marker $\beta$-catenin (not shown). At this point, there was no expression of the beta-cell markers $\mathrm{Pdx} 1$ and insulin. After $48 \mathrm{~h}$ of treatment, immunocytochemistry revealed a translocation of Ngn3 from the cytoplasm to the nucleus (Figure 2c). At this time point, more than $85 \%$ of
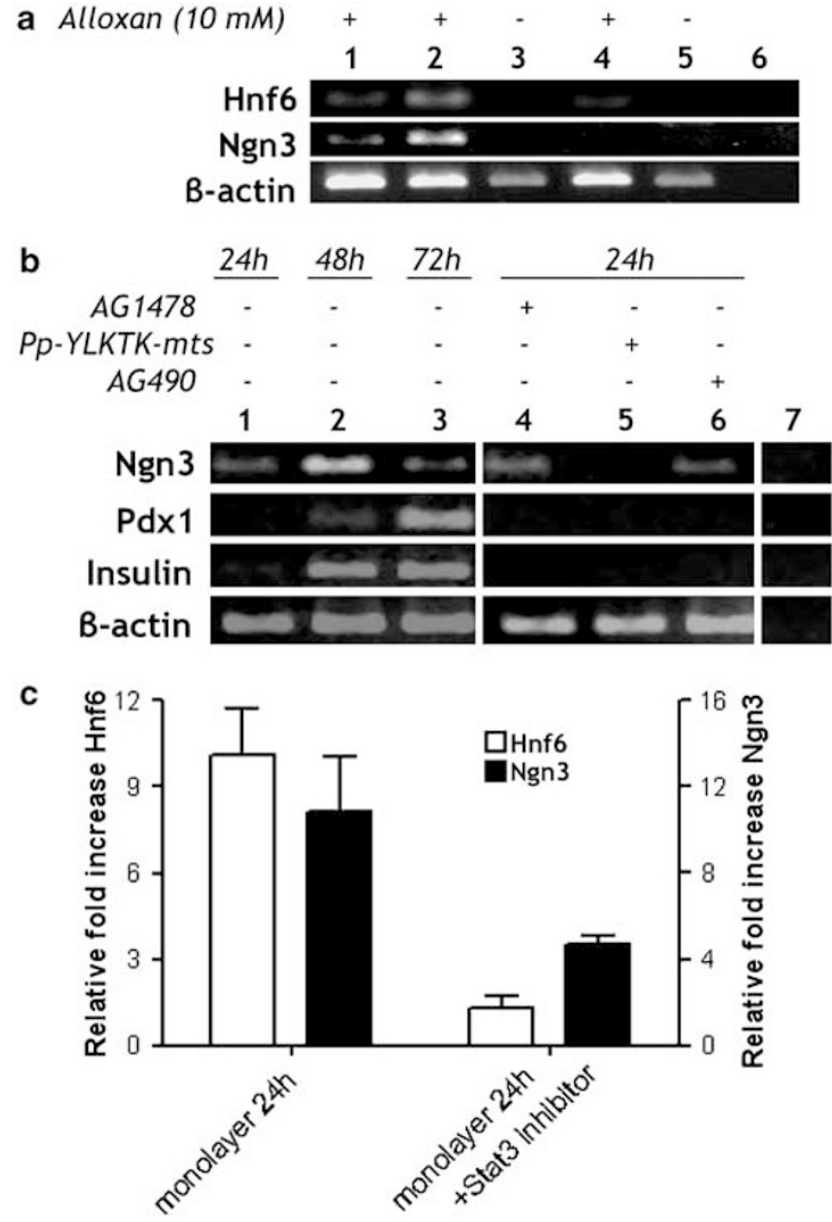

Figure 1 (a) RT-PCR analysis of $\mathrm{Hnf} 6$ and Ngn3 expression in cultures treated for $72 \mathrm{~h}$ with control medium (1) or with growth factor supplemented medium (2). Additional controls are normal rat pancreas (3), cell cultures before growth factor addition (4), rat islets (5) and negative control (water). (b) Transient expression of $\mathrm{Ngn} 3, \mathrm{Pdx} 1$ and insulin at $24 \mathrm{~h}(1), 48 \mathrm{~h}$ (2) and $72 \mathrm{~h} \mathrm{(3)} \mathrm{after} \mathrm{growth} \mathrm{factor}$ addition. The mRNA levels after $48 \mathrm{~h}$ of growth factor addition were compared to cultures treated with inhibitors AG1478 (4), Pp-YLKTK-mts (5) or AG490 (6). (c) Cell cultures after $24 \mathrm{~h}$ of treatment with growth factors + Pp-YLKTK-mts (STAT3 inhibitor) were compared to inhibitor-untreated cultures at the same time points

the Ngn3-positive cells showed nuclear staining and cells appeared in the culture that coexpressed $\mathrm{Ngn} 3$ and insulin (Figure 2c). In all $\mathrm{Ngn} 3+$ cells that coexpressed insulin (7.4 $+1.1 \%, n=3 ; P<0.01)$, no cytoplasmic but only nuclear localization of the transcription factor was observed. None of the Ngn3 positive cells expressed cytokeratin20 or betacatenin at this time (not shown). During the following $24 \mathrm{~h}$, all Ngn3 was translocated to the nucleus and all the Ngn3positive cells also expressed insulin (Figure 2c). Another $24 \mathrm{~h}$ later, Ngn3 protein had disappeared (not shown).

\section{Ngn3 gene silencing}

To investigate whether the observed transient re-expression of Ngn3 is required for the differentiation of insulin-expressing cells in our culture model, we developed a lentivirus containing Ngn3-specific siRNA ${ }^{21}$ and eGFP as a reporter. Cells were 
A
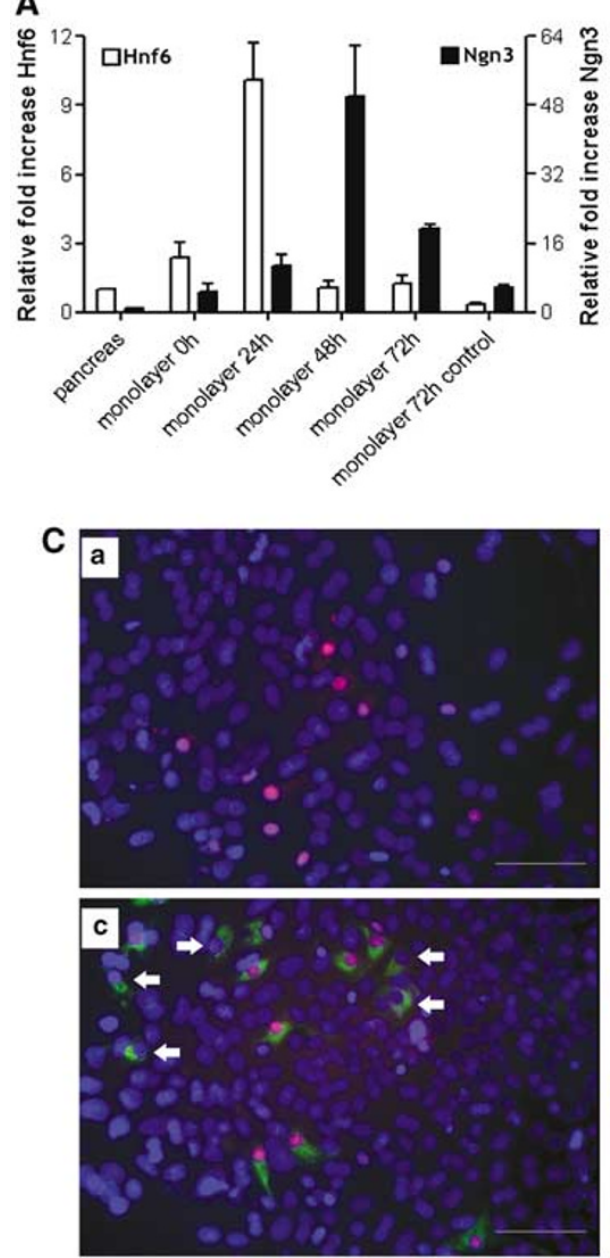

B
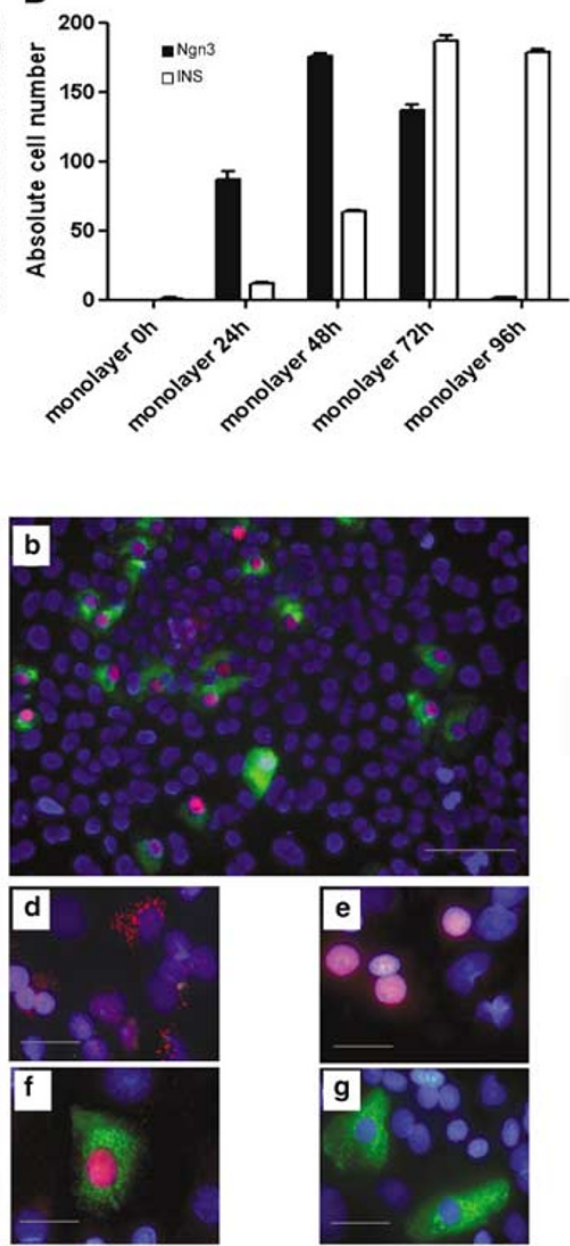

Figure 2 (A) Analysis of Hnf6 and Ngn3 by qPCR. All samples are normalized to $\beta$-actin and to the maximum expression. Analysis was performed on normal pancreas, and on cell cultures after $0,24,48$ and $72 \mathrm{~h}$ of treatment with growth factors, or $72 \mathrm{~h}$ in control medium. (B) Immunocytochemical analysis of Ngn 3 and insulin-expressing cells represented as total number of immunoreactive cells per culture well. Cultures before addition of growth factors and after $24,48,72$ and $96 \mathrm{~h}$ of growth factor treatment. (C) Triple immunocytochemical analysis of $\mathrm{Ngn} 3$ (red) and insulin (green) in growth factor treated cultures. DNA is visualized using DAPI (blue). At $48 \mathrm{~h}$ after addition of growth factors, Ngn3 is mostly located in the nucleus of insulin-negative cells (Panel a), but some insulin-positive cells coexpress Ngn3 (Panel b). At $72 \mathrm{~h} \mathrm{after}$ addition of growth factors, some cells show positivity for both $\mathrm{Ngn} 3$ and insulin, whereas others are insulin-positive but Ngn3-negative (arrows) (Panel c). Panels $\mathrm{d}-\mathrm{g}$ show higher magnification images of cells expressing Ngn3 in their cytoplasm after $24 \mathrm{~h}$ of treatment (d), nuclear Ngn3 expression preceding the insulin expression after $48 \mathrm{~h}(\mathbf{e})$, coexpression of $\mathrm{Ngn} 3$ and insulin after $72 \mathrm{~h}(\mathbf{f})$ and absence of $\mathrm{Ngn} 3$ in the insulin-immunoreactive cells after $96 \mathrm{~h}$ of EGF $+\mathrm{LIF}$ treatment $(\mathbf{g})$. Bar $=30 \mu \mathrm{m}$ $(\mathrm{a}-\mathrm{c}) ; 5 \mu \mathrm{m}(\mathrm{d}-\mathrm{g})$

infected with either a control virus expressing scrambled siRNA or one of two vectors containing silencing siRNA specifically directed against Ngn3. The efficiency of the siRNA constructs to silence Ngn3 was tested in 293T cells transfected with HA-tagged mouse Ngn3-encoding plasmid and in which the appropriate siRNAs (control or Ngn3specific) were expressed (Figure 3a). HA-Ngn3 protein was abundantly expressed in cells in which control plasmid was introduced but was undetectable (Ngn3-si1) or significantly decreased (Ngn3-si2) in the presence of the specific siRNAs (Figure 3a).

Pancreatic acinar cells were infected and analyzed 4 days later, after $72 \mathrm{~h}$ of treatment with EGF and LIF. The efficiency of the lentiviral transduction was around $20 \%$ for all viruses tested. In cultures transduced with control virus, $19.1 \pm 2.5 \%$ of the insulin-positive cells $(9.9 \pm 0.6 \%$ of total cells) coex- pressed eGFP. In cultures transduced with LeNgn3-si1 only $0.2 \pm 0.2 \%$ of insulin-positive cells coexpressed eGFP $(7.8 \pm 0.3 \%$ insulin-positive of total cell number $)(P<0.001$; $n=4)$. In cultures transduced with LeNgn3-si2 there was also a significant reduction in the insulin/eGFP coexpressing cells $(8.1 \pm 0.4 \%$ in the total cell population) (Figure $3 c)$. The total number of insulin-positive cells was also reduced by Ngn3 silencing, although the values did not reach statistical significance (due to the relatively low transduction efficiency of $20 \%)$.

\section{Role of JAK/STAT- signalling in Ngn3 expression}

We examined the contribution of EGF- and LIF-activated signal-transduction pathways to the induction of $\mathrm{Ngn3}$, and subsequent insulin gene expression. LIF effects are mediated 
a

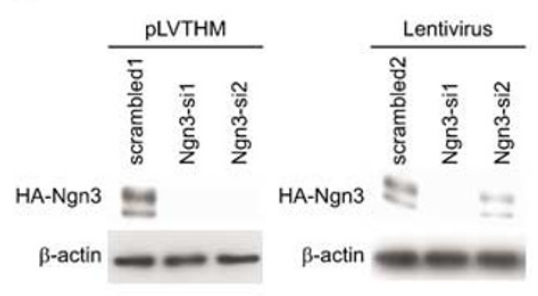

b

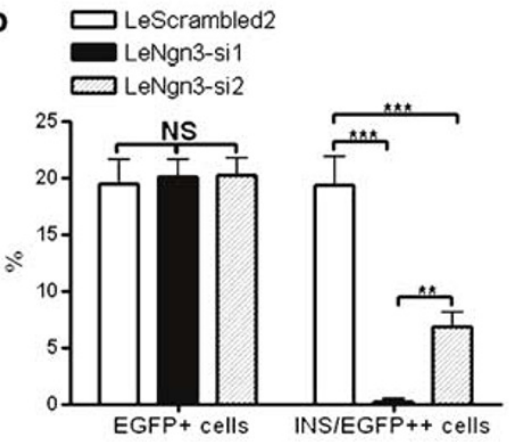

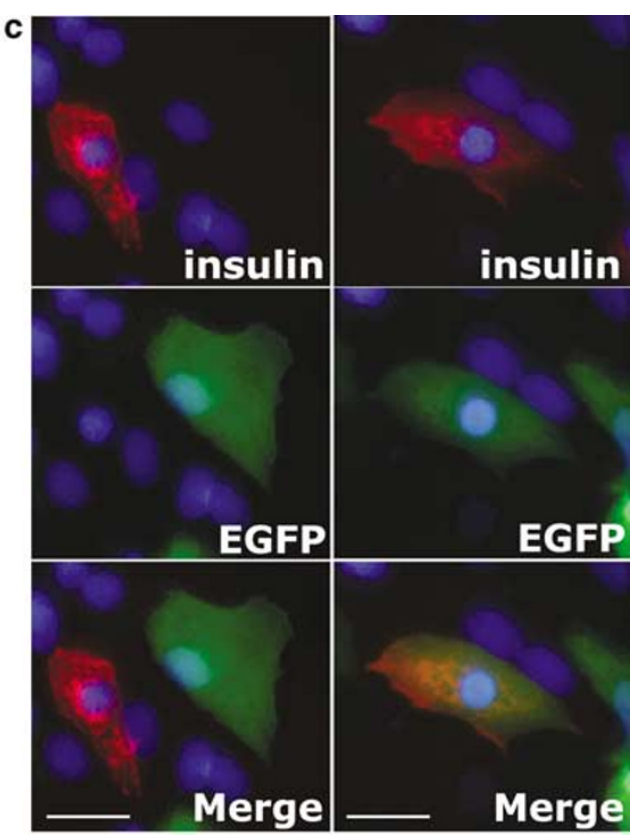

Figure 3 293-T cells were transfected with the appropriate pLVTHM constructs and an HA-tagged mouse Ngn3 encoding plasmid (pAdTrackCMV-HA-mmNgn3) in a 5:1 ratio. Transfection with the pLVTHM constructs was 1 day before pAdTrackCMV-HA-mmNgn3 transfection to allow sufficient generation of siRNA molecules. (a) Western-blot analysis shows that HA-Ngn3 is abundantly expressed in the scrambled1 sample. In contrast, its expression is undetectable in the Ngn3-si1 and Ngn3-si2 samples. Prolonged exposures (overnight) sometimes revealed a faint Ngn3 signal in the Ngn3-si2 sample. Similarly, 293 T cells were transduced with the appropriate lentivirus (MOI 5) 1 day before transfection with pAdTrackCMV-HA-mmNgn3. Again, clear Ngn3 expression is present in the negative control sample, scrambled2. Lentivirus-mediated Ngn3 RNAi results in absence of Ngn3 expression using the Ngn3-si1 coding virus. Ngn3 suppression also occurs in the Ngn3-si2 virus transduced sample, though to a lesser extent. Control b-actin detections are included. (b) Functional silencing of Ngn3 in acinar cell cultures. Cells are stably infected with LeNgn3-si or LeScrambled2 at $\sim 20 \%$ efficiency at day 4 (before monolayer formation). EGFP expression was analyzed at day 8 by fluorescence imaging. No differences in transduction efficiency of the total cell population could be detected between the different constructs used $(P>0.05 ; n=3)$. When analyzing coexpression of eGFP with insulin, significant differences could be detected between the control and the Ngn3 silencing conditions $(P<0.001 ; n=3)$. Analysis of the specific silencing conditions revealed a difference in their ability to silence Ngn3 $(P<0.01 ; n=3)$. (c) Immunocytochemical analysis of insulin in Ngn3 RNAi (left panels) and control RNAi (right panels) infected primary cells. No insulin-positive cell was found to express EGFP in the Ngn3 RNAi infected condition. In control RNAi infected conditions $\sim 20 \%$ of the insulin-positive cells coexpressed EGFP. Bar $=10 \mu \mathrm{m}$

via STAT3 phosphorylation. ${ }^{22}$ Therefore, we analyzed the effect of Pp-YLKTK-mts, a potent inhibitor of STAT3 activation. ${ }^{23}$ Inhibition of activated STAT3 resulted in 2.3-fold decreased Ngn3 transcript levels $(P<0.05 ; n=3)$ (Figure $1 \mathrm{~b}$ ) and in decreased numbers of Ngn3-immunopositive cells $(0.12 \pm 0.02 \%$ compared to $4.78 \pm 0.28 \%$ in the absence of inhibitor; $n=3 ; P<0.001$ ) (Figure $4 \mathrm{a}$ ). After $72 \mathrm{~h}$ of STAT3-inhibitor treatment, the number of insulin-expressing cells is also strongly reduced $(0.3 \pm 0.07 \%$ in the presence of inhibitor compared to $9.2 \pm 1.5 \%$ in the absence of inhibitor; $n=3 ; P<0.01$ ) (Figure 4b).

The contribution of JAK activity to tyrosine phosphorylation of STAT3 was investigated by treatment of the cultures with the JAK inhibitor AG490. ${ }^{24}$ A 24-h incubation with the inhibitor induced a marked reduction in Ngn3 transcript levels (Figure 1b) and protein expression following stimulation with EGF and LIF $(4.78 \pm 0.28 \%$ in control cells versus $0.51 \pm 0.05 \%$ after AG490 treatment $(n=3 ; P<0.01))$ (Figure 4a). Seventy-two hours after addition of AG490, the percentage of insulin positive cells was reduced from $9.2 \pm 1.5 \%$ to $1.1 \pm 0.1 \%$, which corresponds to a $88 \%$ reduction in beta-cell neogenesis $(P<0.01)$ (Figure $4 b)$.

As EGF-receptor (EGFR) signalling is at least partly responsible for the beta-cell neogenesis and may control the responsiveness of LIF-induced STAT3 activation, ${ }^{25}$ the effect of $A G 1478$, a selective antagonist of the $\mathrm{EGFR}^{26}$ on growth factor-induced expression of $\mathrm{Ngn} 3, \mathrm{Pdx} 1$ and insulin was examined. Inhibition of EGFR signalling by AG1478 induced only a minor decrease in Ngn3 mRNA expression (Figure 1b). However, the EGFR-inhibitor lowered the number of Ngn3immunoreactive cells (Figure 4 a) as well as the number of insulin-immunoreactive (Figure $4 \mathrm{~b}$ ) cells by $80 \%$ $\left(0.90 \pm 0.08 \% \mathrm{Ngn}^{+}\right.$and $1.6 \pm 0.05 \%$ insulin $^{+}$cells following EGFR inhibition versus $4.78 \pm 0.28 \% \mathrm{Ngn}^{+}$and $9.2 \pm 1.5 \%$ insulin $^{+}$cells under control conditions, $n=3$; $P<0.01)$. The effectiveness of the different inhibitors to attenuate protein phosphorylation was confirmed by immunoblot analysis (Figure 4c).

\section{Growth factor-induced upregulation of Hnf6}

During embryonic development, the onecut transcription factor hepatocyte nuclear factor-6 (Hnf6) controls the expression of Ngn3. ${ }^{20}$ Low amounts of $\mathrm{Hnf} 6$ transcript are detected by RT-PCR ( 28 cycles of amplification) in control cultures at days 5 and 8, whereas Hnf6 mRNA levels increased after stimulation by EGF and LIF together but not alone (Figure 1a). The time dependence of Hnf6 expression was analyzed by qPCR at $0 \mathrm{~h}$ (control), $24 \mathrm{~h}, 48 \mathrm{~h}$, and $72 \mathrm{~h}$ after addition of both growth factors. Hnf6 gene expression was 10-fold increased 

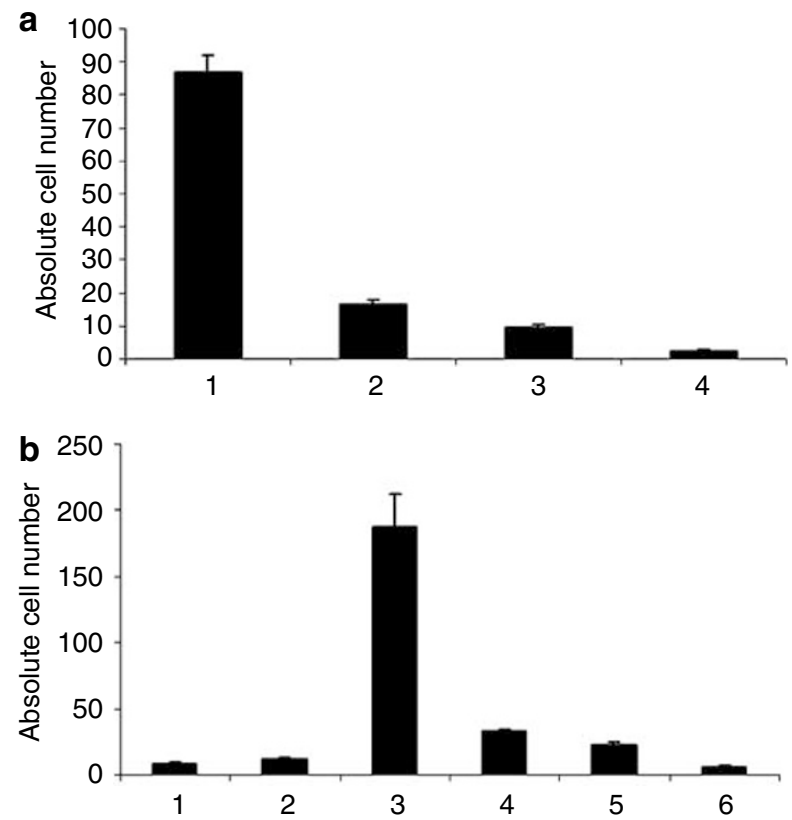

c Inhibitor Phosphorylated
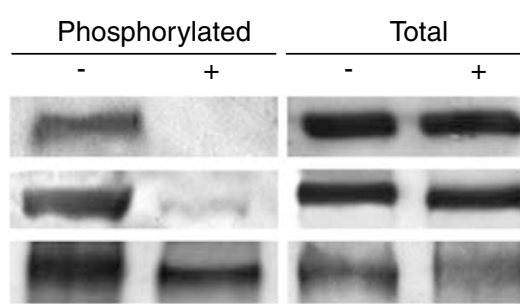

Figure 4 (a) The effect of different inhibitors on the expression of Ngn3 protein: $24 \mathrm{~h}$ of treatment with EGF and LIF without inhibitor (1) or with AG1478 (2), AG490 (3) or Pp-YLKTK-mts (4). (b) Insulin protein expression after $72 \mathrm{~h}$ in untreated conditions (control medium only) (1) and conditions treated with EGF (2), EGF + LIF (3), EGF + LIF + AG1478 (4), EGF + LIF + AG490 (5) and EGF + LIF + Pp-YLKTK-mts (6). Data are the means \pm S.D. of three independent experiments with triplicate measurements. (c) Effectiveness of different inhibitors on EGF- and LIF-activated signal transduction. Inhibition of protein phosphorylation by use of pharmacological inhibitors was confirmed using Western-blot analysis. Use of Pp-YLKTK-mts (inhibitor of phospho-STAT3), AG490 (inhibitor of phospho-JAK2) and AG1478 (inhibitor of phospho-EGFR) in EGF- and LIF- treated cultures clearly attenuated protein phosphorylation as compared to control cultures (only EGF and LIF treated)

$24 \mathrm{~h}$ after addition of growth factors as compared to normal rat pancreas $(P<0.01 ; n=3)$ and 4.3-fold compared to unstimulated cultures. Remarkably, Hnf6 was already significantly decreased $48 \mathrm{~h}$ after addition of growth factors. This downregulation continues until day 8 (Figure 2a). Growth factorinduced Hnf6 gene expression in cultures was markedly reduced in the presence of the inhibitor of STAT-activation PpYLKTK-mts (7.5-fold decrease at day $6(P<0.01 ; n=3))$ (Figure 1c). In the presence of nicotinamide in the medium, an agent which was shown to delay the loss of exocrine cell markers, ${ }^{8,11}$ we found that $10-20 \%$ of all cells expressed $\mathrm{Hnf} 6$ in the nucleus. Sixty percent of these cells coexpressed CK20 and $45 \%$ coexpressed the acinar marker lipase (some Hnf6positive cells expressed both CK20 and lipase) (Figure 5). These observations support our hypothesis of a transdifferentiation from exocrine acinar to endocrine beta cells. ${ }^{11}$
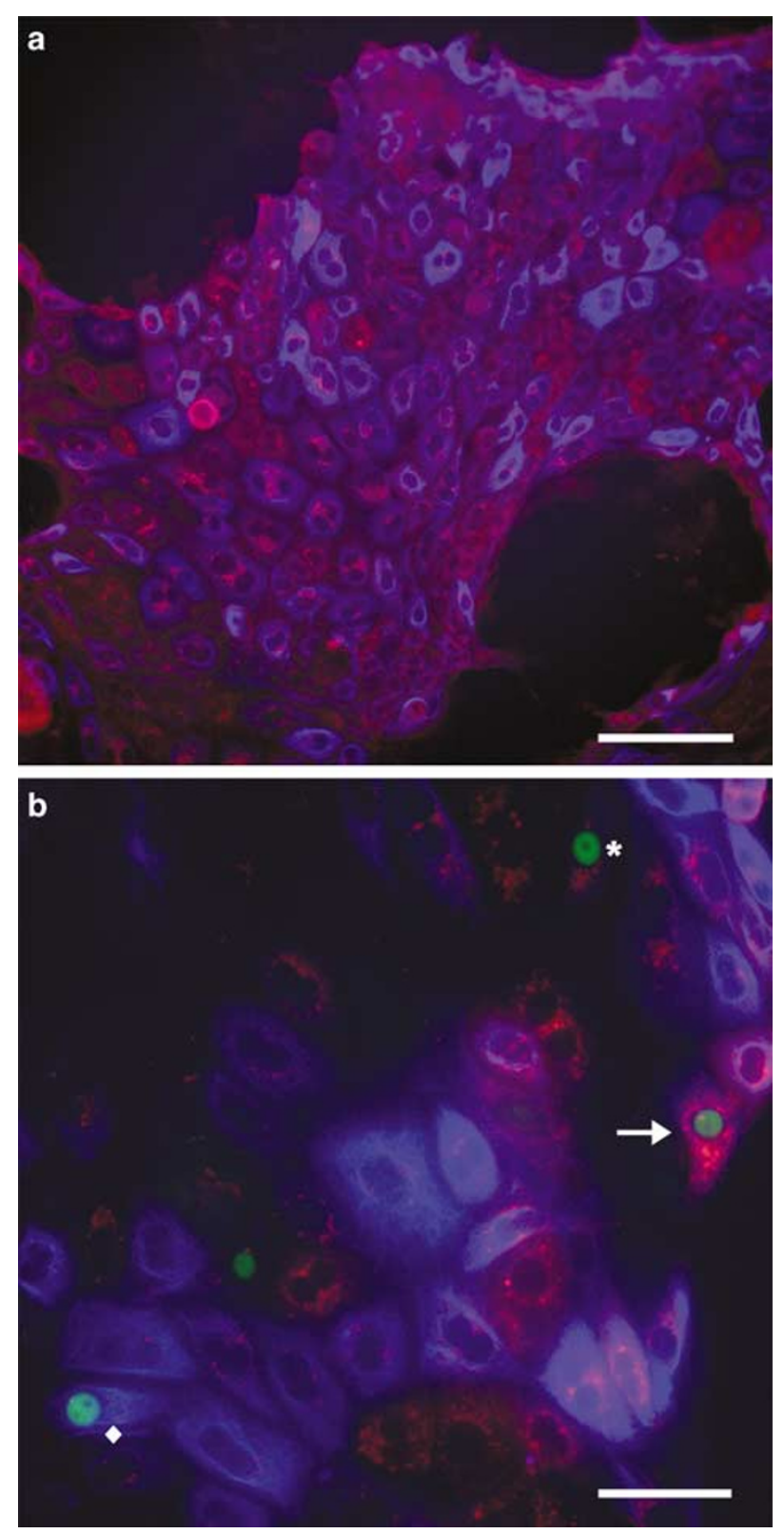

Figure 5 Triple immunocytochemical analysis of lipase (red), HNF6 (green) and CK20 (blue) in nicotinamide-treated cultures. $24 \mathrm{~h}$ after addition of control medium (a) or growth factor supplemented medium (b), HNF6 shows nuclear localization in cells expressing lipase $\left({ }^{*}\right)$, CK20 $(\diamond)$ or in cells expressing both markers (arrow), only in growth factor-treated cultures. Bar $=30 \mu \mathrm{m}$ (a); $15 \mu \mathrm{m}$ (b)

\section{Discussion}

We have previously developed and validated an in vitro model for beta-cell regeneration by stimulation of dedifferentiated exocrine cells with a combination of EGF and LIF. ${ }^{11}$ Upon treatment with both growth factors, an important increase in the absolute number of beta cells was seen (60-fold in 3 days). This could not have been due to beta-cell replication which was extremely low. Transitional stages of differentiation indicated that new beta cells arose from transdifferentiation of acinar cells. ${ }^{11} \mathrm{~A}$ recent report confirmed this transdiffer- 
entiation phenomenon by genetic lineage tracing. ${ }^{27}$ The present study aimed at understanding the molecular mechanism involved in this in vitro beta-cell neogenesis model. Studies on the embryonic development of the endocrine pancreas have shown that a transient expression of the basic helix-loop-helix transcription factor Ngn3 drives the proendocrine fate. ${ }^{15,16,28}$ Ectopic expression of $\mathrm{Ngn} 3$ in adult exocrine ductal cells leads to a partial recapitulation of endocrine differentiation. ${ }^{19}$ In normal pancreas, freshly isolated exocrine tissue and cultured exocrine cells, Ngn3 mRNA was absent. Our study demonstrates that stimulation of the exocrine cells with both EGF and LIF activated Ngn3 gene expression. Pre-existing beta cells were eliminated by the toxin alloxan, which also induced Ngn3 expression, be it at low level (sixfold lower when compared to the corresponding condition treated with EGF and LIF). In a separate experiment, cells were not pretreated with alloxan and in this case Ngn3 mRNA could no longer be detected unless EGF and LIF were both supplemented to these cultures (data not shown). Ngn3 protein expression was detected by immunocytochemistry, however, exclusively when EGF and LIF were both supplemented to the culture medium. Insulin mRNA and protein were undetectable in cells that were treated with alloxan only, but were readily detectable after treatment with growth factors. This is in accordance with our previous finding that neogenesis of insulin immunoreactive beta cells only occurs in the presence of both growth factors. ${ }^{11}$ The observation that, in the absence of growth factors, alloxaninduced increase in Ngn3 mRNA expression is not mirrored by an increase in protein expression may be explained by the difference in sensitivity of the detection techniques. In addition, large discrepancies between mRNA and protein levels may exist in cells, but most studies on Ngn3 expression so far focused on its transcriptional regulation. Ngn3 protein was first detected by immunocytochemistry $24 \mathrm{~h}$ after treatment with EGF and LIF. At this time point, Ngn3 was mainly located in the cytoplasm, as has also been seen during embryonic development in rat at E15 (unpublished observations). Two days later, Ngn3 translocated to the nucleus, as it does during normal endocrine development. However, in contrast to the normal beta-cell development, during which Ngn3 and markers for differentiated beta cells like Pdx1 and insulin never are coexpressed, Ngn3 and insulin were observed together in the same cells between day 2 and 4 following treatment with EGF and LIF. ${ }^{15,29,30}$ This is very unusual, since normally Ngn3 represses its own expression and thus activates the differentiation process, but does not complete it. ${ }^{31}$ The temporary coexpression of $\mathrm{Ngn} 3$ and insulin in our in vitro model for beta-cell neogenesis is a striking difference with the expression pattern during embryogenesis of the endocrine pancreas which cannot be explained by our present data. The expression of Ngn3 could be prevented by inhibiting signal-transduction pathways involved in EGF and LIF signalling, namely by inhibiting EGFR, JAK2 and STAT3. This inhibition of Ngn3 subsequently led to a marked decrease in the beta-cell neogenesis normally seen after EGF + LIF treatment. Inhibition of JAK/ STAT induced a stronger downregulation of Ngn3 than inhibition of the EGFR. This is in agreement with what has been described during neurogenesis, where it was found that EGF enhances the responsiveness of LIF-activated signal transduction, the effect being mediated by STAT3 phosphorylation. ${ }^{25}$

To validate the requirement of $\mathrm{Ngn} 3$ in inducing the differentiation of insulin-positive cells we have set up a system to silence the Ngn3 gene expression using lentivirusmediated RNAi that targets Ngn3. RNAi is an efficient means to manipulate gene function ${ }^{32,33}$ and the use of a lentivirus allows for the transduction of non-cycling cells. ${ }^{34}$ Control virus and virus that expressed the specific Ngn3 siRNA transduced the cells at same efficiency $(\sim 20 \%)$. However, no insulinpositive cells coexpressing eGFP could be found after transduction with LeNgn3-si1, whereas in controls $19 \%$ of the insulin-positive cells were labelled with the fluorescent reporter. This indicates that lentivirus-driven expression of this siRNA efficiently silenced Ngn3 gene expression in transduced cells and that silencing of Ngn3 expression prevents the neogenesis of beta cells.

The exact nature of the upstream activators of $\mathrm{Ngn} 3$ is still unclear, but it has been shown that the transcription factor Hnf6 controls the expression of Ngn3 during development, and that Hnf6 knockout mice still express Ngn3, but at reduced levels. ${ }^{20}$ It is well described that $\mathrm{Hnf} 6$ is present in the acinar and ductal cells of the adult pancreas. ${ }^{35}$ However, immunocytochemical analyses indicated that in our in vitro culture model, Hnf6-expression in the dedifferentiated exocrine cells could no longer be shown. After stimulation of our cultures with EGF and LIF, a transient upregulation of Hnf6 was detected, that immediately preceded the Ngn3 expression. It is possible that EGF + LIF signalling via the JAK/STAT pathway upregulates Hnf6 which in turn induces the transient expression of $\mathrm{Ngn} 3$. It is known that Hnf6 gene expression can be upregulated by growth hormone treatment via activation of STAT5. ${ }^{36}$ Hnf6 upregulation via STAT3 is not yet described, but after treatment of our cells with the selective inhibitor of STAT3 (Pp-YLKTK-mts), Hnf6 mRNA expression was decreased 10-fold as compared to controls. The observation of cells coexpressing Ngn3 and CK20, a marker of duct cells and dedifferentiated acinar cells, suggest that dedifferentiated acinar cells represent the progenitor cells that started to express Ngn3. Additionally, after treatment of the cultures with nicotinamide to delay the loss of acinar characteristics, ${ }^{8,11}$ we could detect Hnf6 protein expression in the nucleus of cells expressing CK20 and/or the acinar cell marker lipase. This confirms our hypothesis that acinar exocrine cells of the pancreas harbour a remarkable plasticity and can serve as endocrine progenitors. ${ }^{11}$ In conclusion, we demonstrate that EGF and LIF signalling via the JAK/STAT pathway induces a transient re-expression of the embryonic pro-endocrine transcription factor $\mathrm{Ngn} 3$ in adult pancreatic cells. Adult beta-cell neogenesis in vitro at least partially recapitulates the embryonic molecular pathway by being dependent on reexpression of $\mathrm{Ngn} 3$.

\section{Materials and Methods}

\section{Animals and isolation procedure}

Male 10-12 week old Wistar rats (Janvier, Le Genest-St-Isle, France) weighing 250-300 $\mathrm{g}$ were used for the isolation of cells from the pancreas. 
Pancreata were partially dissociated with collagenase and exocrine acini were purified by centrifugal elutriation as published before ${ }^{8,35}$ All animal experimentation was approved by the Ethical Committee of the Free University of Brussels. Cell Culture Exocrine cells were pre-cultured for 4 days in bacteriological Petri dishes (Nunc, Naperville, IL, USA) in suspension culture in RPMI-1640 Glutamax-I medium supplemented with $10 \%$ foetal bovine serum (FBS, Gibco BRL, Paisley, Scotland), penicillin (75 mg/l) (Continental Pharma, Brussels, Belgium) and antibiotics (Sigma, St Louis, MO, USA). Geneticin sulphate ( $50 \mu \mathrm{g} / \mathrm{ml})$ (Sigma) was used to suppress fibroblasts from the culture. Medium was replaced daily during this preculture period. At the end of the preculture, cells were treated with alloxan $\left(10 \mathrm{mM}\right.$, Sigma) for $10 \mathrm{~min}$ at $37^{\circ} \mathrm{C}$ to remove contaminating beta cells, and transferred to 24-well plates (Falcon, BD Biosciences, Erembodegem, Belgium) for adherent culture. Adherent monolayers were further cultured with RPMI supplemented with 1\% FBS and antibiotics (controls). For growth factor stimulation of neogenesis this medium was supplemented with $50 \mathrm{ng} / \mathrm{ml}$ human recombinant epidermal growth factor (EGF) (Sigma, St Louis, MO) and $40 \mathrm{ng} / \mathrm{ml}$ recombinant mouse leukaemia inhibitory factor (LIF) (Sigma). ${ }^{20}$ Signal transduction inhibition assays were performed using a selective EGFR inhibitor (AG1478, $10 \mu \mathrm{M}$, Sigma), a JAK2 inhibitor (AG490, $20 \mu \mathrm{M}$, Sigma) and a phospho-STAT3 inhibitor (Pp-YLKTK-mts, $2.5 \mu \mathrm{M}$, Calbiochem). Cell monolayers were analyzed after a culture period of 3 days in the latter media. At these concentrations, no toxic effects of the inhibitors were noted on the epithelial monolayers. Some cultures were treated with nicotinamide $(10 \mathrm{mM})$ (Sigma) to partially prevent the loss of exocrine markers normally seen during the acino-ductal transdifferentiation. ${ }^{8}$

\section{Immunocytochemistry}

Immunocytochemical staining of the monolayers was performed directly in the 24-well plates. For this purpose, the cell monolayers were fixed for $10 \mathrm{~min}$ with $4 \%$ buffered formaldehyde followed by $20 \mathrm{~min}$ methanol $\left(-20^{\circ} \mathrm{C}\right)$ for cell permeabilization. Primary antibodies used in this study are polyclonal anti-insulin (C. Van Schravendijk, VUB, Brussels), ${ }^{36,37}$ polyclonal anti-rat C-peptide-I (O.D. Madsen, Hagedorn Research Institute, Gentofte, Denmark), ${ }^{38}$ polyclonal anti-Pdx1 (O.D. Madsen) ${ }^{8}$, polyclonal anti-Ngn3, ${ }^{16}$ monoclonal anti-cytokeratin-20 (CK20) (Novocastra, Newcastle-upon-Tyne, UK), ${ }^{36,37}$ monoclonal anti- $\beta$-catenin (BD Biosciences, Erembodegem, Belgium), ${ }^{39}$ polyclonal anti-Hnf6 (Santa Cruz Biotechnology, CA, USA) ${ }^{40}$ and polyclonal anti-lipase (Biodesign International, Maine, USA). Secondary antibodies conjugated with fluorescein isothiocyanate, tetramethylrodamine isothiocyanate or Cy5 (Jackson Immunoresearch, West Grove, PA) were used as described previously. ${ }^{11}$ Imaging was performed using Zeiss Axiovision Software. RNA isolation, RT-PCR and qPCR total RNA was isolated from cells and tissues using the GenElute Mammalian Total RNA miniprep kit (Sigma). For the semi-quantitative analysis of transcripts encoding insulin, neurogenin3 (Ngn3), pancreatic and duodenal homeobox1 (Pdx1), hepatocyte nuclear factor- 6 (Hnf6) and beta-actin, the total RNA was reversed transcribed and amplified as described by the manufacturer (Gibco BRL) with blanks in each assay. Primers were designed to anneal to specific sequences of rat insulin- $5^{\prime}$ : caatcatagaccatcagcaagc and insulin-3': tttattcattgcagaggggtgg, NGN3-5': gaaatggaaggtagtggaggca and NGN3-3': agccagtgaggtaagacgcaac, PDX1-5': ctcgctgggaacgctggaaca and PDX1-3': ctttggtggatttcatccacgg, HNF-6-5': aagccctggagcaaactcaa and HNF-6-3': tctgtccttcccgtgttctt. Specific primers for control amplifications were beta-actin-5': ccccattgaacacggcatt and beta-actin- $3^{\prime}$ : ggtcatctttcacggttggc. The cycling profile was $1.5 \mathrm{~min}$ at $94^{\circ} \mathrm{C}$ followed by $0.5 \mathrm{~min}$ at $94^{\circ} \mathrm{C}, 0.5 \mathrm{~min}$ at $60^{\circ} \mathrm{C}$ and $1 \mathrm{~min}$ at $72^{\circ} \mathrm{C}$ for 10 cycles and
$0.5 \mathrm{~min}$ at $94^{\circ} \mathrm{C}, 0.5 \mathrm{~min}$ at $58^{\circ} \mathrm{C}$ and $1 \mathrm{~min}$ at $72^{\circ} \mathrm{C}$ for $16-20$ cycles (total of 22 cycles for insulin, 28 cycles for HNF6, 30 cycles for NGN3, 32 cycles for PDX1 and 30 cycles for b-actin). Analysis of the amplified fragments was done on ethidium bromide-stained agarose gels. All analyses were performed at least three times. Target genes selected from RT-PCR were further analyzed using qPCR to quantify their expression level. cDNA was prepared from $500 \mathrm{ng}$ total RNA following DNase treatment and $10 \mathrm{ng}$ RNA equivalent used for PCR with selected primers in the presence of SYBR Green. A melt-curve analysis was performed for each reaction. The expression levels were normalized to individual beta-actin (internal control) and to normal rat pancreas (reference).

Lentivirus-mediated RNA interference Ngn3-specific RNAi target sequences were developed using dedicated software available through the Whitehead Institute for Biomedical Research website (http:// jura.wi.mit.edu/bio/). ${ }^{37}$ Corresponding oligo DNA molecules (Eurogentec) were cloned in the Bglll and Hindlll sites of the pSuper.basic vector (Oligoengine). Insert-containing clones were PCR-selected and sequenced. DNA from clones containing correct inserts was EcoRI-Clal cut, which released a DNA fragment containing the $\mathrm{H} 1$ promoter and the cloned oligo duplex, which was subsequently subcloned in the EcoRI-Clal sites of the pLVTHM vector. ${ }^{21}$ Screening for RNAi activity of the constructs was performed as follows: $293 \mathrm{~T}$ cells were plated at $70 \%$ confluency in 24-well plates at day 0 . After allowing the cells to attach, $500 \mathrm{ng}$ DNA of the appropriate pLVTHM constructs was transfected per well. A measure of $100 \mathrm{ng}$ pAdTrackCMV-HA-mmNgn3 plasmid DNA was transfected per well the following day. The latter construct encodes HA-tagged mouse Ngn3 (Heremans et al., 2003). After an additional $24 \mathrm{~h}$, cells were processed for Western-blot analysis, in which $10 \mu \mathrm{g}$ total protein was used per lane. In these assays, the Ngn3 protein was detected using an anti-HA tag antibody (Sigma). Constructs that displayed sufficient RNAi activity were used for lentivirus generation according to standard techniques. ${ }^{21}$ Two constructs, Ngn3-si1 and Ngn3-si2, were selected for further use in Ngn3 RNAi experiments, generating lentivirus LeNgn3-si1 and LeNgn3si2, respectively. The Ngn3-si1 target sequence is gtgctcagttccaattcca, and the Ngn3-si2 target sequence is gaccctgcgcttcgcccac. The selected target sequences match 100\% with both mouse and rat Ngn3 mRNA sequences. Negative control RNAi constructs were scrambled1 (gag catgcgagccatgcac) and scrambled2 (TCGTCATAGCGTGCATAGG). Primairy acinar exocrine cells were transduced at $19.4 \pm 2.2 \%$ efficiency after infection with LeScrambled2, at $20.1 \pm 1.5 \%$ efficiency after infection with LeNgn3-si1 and at $20.2 \pm 1.5 \%$ efficiency after infection with LeNgn3si2 $(n=4)$ statistics We used a two-tailed, paired Student's $t$-test and considered statistical significance at a confidence interval $<0.05$. Mean values are given \pm S.E.M. Number of independent experiments is indicated in the text.

\section{Acknowledgements}

This work was supported by a Focused Research Grant from EFSD/JDRF/ Novo Nordisk. Additional support was obtained from the Fund for Scientific Research-Flanders (FWO-grant G001502 to L. Bouwens and G006402 to $\mathrm{HH})$, the Juvenile Diabetes Research Foundation $(\mathrm{HH})$ and the Larry $\mathrm{L}$. Hillblom Foundation grant No. 2002/1(E) (MSG). We are grateful to Dr Daniël Pipeleers for general and logistic support. We thank Emmy De Blay and Marijke Baekeland for their help in immunocytochemistry, and Dr I Rooman, Dr J Lardon, Dr JK Mfopou and S De Breuck for helpful discussions. L. Baeyens is a research fellow of the Institute for the Promotion of Innovation through Science and Technology in Flanders (IWT-Vlaanderen), SB is a post-doctoral fellow of the FWO-Vlaanderen. 


\section{References}

1. Dor Y, Brown J, Martinez OI and Melton DA (2004) Adult pancreatic beta-cells are formed by self-duplication rather than stem-cell differentiation. Nature 429 : 41-46.

2. Bonner-Weir S, Baxter LA, Schuppin GT and Smith FE (1993) A second pathway for regeneration of adult exocrine and endocrine pancreas. A possible recapitulation of embryonic development. Diabetes 42: 1715-1720.

3. Bonner-Weir S and Sharma A (2002) Pancreatic stem cells. J. Pathol. 197: 519-526.

4. Kodama S, Kuhtreiber W, Fujimura S, Dale EA and Faustman DL (2003) Islet regeneration during the reversal of autoimmune diabetes in NOD mice. Science 302: 1223-1227.

5. Rooman I, Lardon J and Bouwens L (2002) Gastrin stimulates beta-cell neogenesis and increases islet mass from transdifferentiated but not from normal exocrine pancreas tissue. Diabetes 51: 686-690.

6. Rooman I and Bouwens L (2004) Combined gastrin and epidermal growth factor treatment induces islet regeneration and restores normoglycaemia in C57BI6/J mice treated with alloxan. Diabetologia 47: 259-265.

7. Lardon J, De BS, Rooman I, Van LL, Kruhoffer M, Orntoft T, Schuit F and Bouwens $L(2004)$ Plasticity in the adult rat pancreas: transdifferentiation of exocrine to hepatocyte-like cells in primary culture. Hepatology 39: 1499-1507.

8. Rooman I, Heremans $Y$, Heimberg H and Bouwens L (2000) Modulation of rat pancreatic acinoductal transdifferentiation and expression of PDX-1 in vitro. Diabetologia 43: 907-914.

9. Shen CN, Slack JM and Tosh D (2000) Molecular basis of transdifferentiation of pancreas to liver. Nat. Cell Biol. 2: 879-887.

10. Rooman I (2003) Proliferation and differentiation of adult rat pancreatic exocrine cells. Verh. K. Acad. Geneeskd. Belg. 65: 117-125.

11. Baeyens L, De BS, Lardon J, Mfopou JK, Rooman I and Bouwens L (2005) in vitro generation of insulin-producing beta cells from adult exocrine pancreatic cells. Diabetologia 48: 49-57.

12. Jensen JN, Cameron E, Garay MVR, Starkey TW, Gianani R and Jensen J (2005) Recapitulation of elements of embryonic development in adult mouse pancreatic regeneration. Gastroenterology 128: 728-741.

13. Apelqvist A, Li H, Sommer L, Beatus P, Anderson DJ, Honjo T, de Angelis MH Lendahl U and Edlund H (1999) Notch signalling controls pancreatic cell differentiation. Nature 400: 877-881.

14. Edlund $\mathrm{H}$ (2001) Factors controlling pancreatic cell differentiation and function Diabetologia 44: 1071-1079.

15. Gu GQ, Dubauskaite J and Melton DA (2002) Direct evidence for the pancreatic lineage: NGN3+cells are islet progenitors and are distinct from duct progenitors. Development 129: 2447-2457.

16. Gradwohl G, Dierich A, LeMeur M and Guillemot $F(2000)$ Neurogenin3 is required for the development of the four endocrine cell lineages of the pancreas. Proc. National Acad. Sci. USA 97: 1607-1611.

17. Schwitzgebel VM, Scheel DW, Conners JR, Kalamaras J, Lee JE, Anderson DJ, Sussel L, Johnson JD and German MS (2000) Expression of neurogenin3 reveals an islet cell precursor population in the pancreas. Development 127: 3533-3542.

18. Grapin-Botton A, Majithia AR and Melton DA (2001) Key events of pancreas formation are triggered in gut endoderm by ectopic expression of pancreatic regulatory genes. Genes \& Development 15: 444-454.

19. Heremans Y, Van De CM, in't VP, Gradwohl G, Serup P, Madsen O, Pipeleers $\mathrm{D}$ and Heimberg $\mathrm{H}$ (2002) Recapitulation of embryonic neuroendocrine differentiation in adult human pancreatic duct cells expressing neurogenin 3 . J. Cell Biol. 159: 303-312.

20. Jacquemin P, Durviaux SM, Jensen J, Godfraind C, Gradwohl G, Guillemot F, Madsen OD, Carmeliet P, Dewerchin M, Collen D, Rousseau GG and Lemaigre FP (2000) Transcription factor hepatocyte nuclear factor 6 regulates pancreatic endocrine cell differentiation and controls expression of the proendocrine gene ngn3. Molecular and Cellular Biology 20: 4445-4454.

21. Wiznerowicz M and Trono D (2003) Conditional suppression of cellular genes: lentivirus vector-mediated drug-inducible RNA interference. J. Virol. 77: 8957-8961.
22. Bonni $A$, Sun $Y$, Nadal-Vicens $M$, Bhatt $A$, Frank DA, Rozovsky I, Stahl N, Yancopoulos GD and Greenberg ME (1997) Regulation of gliogenesis in the central nervous system by the JAK-STAT signaling pathway. Science 278 : 477-483.

23. Rojas M, Donahue JP, Tan Z and Lin YZ (1998) Genetic engineering of proteins with cell membrane permeability. Nat. Biotechnol. 16: 370-375.

24. Meydan N, Grunberger T, Dadi H, Shahar M, Arpaia E, Lapidot Z, Leeder JS, Freedman M, Cohen A, Gazit A, Levitzki A and Roifman CM (1996) Inhibition of acute lymphoblastic leukaemia by a Jak-2 inhibitor. Nature 379: 645-648.

25. Viti J, Feathers A, Phillips J and Lillien L (2003) Epidermal growth factor receptors control competence to interpret leukemia inhibitory factor as an astrocyte inducer in developing cortex. J. Neurosci. 23: 3385-3393.

26. Daub H, Weiss FU, Wallasch C and Ullrich A (1996) Role of transactivation of the EGF receptor in signalling by G-protein-coupled receptors. Nature 379: 557-560.

27. Minami K, Okuno M, Miyawaki K, Okumachi A, Ishizaki K, Oyama K, Kawaguchi M, Ishizuka N, Iwanaga T and Seino S (2005) Lineage tracing and characterization of insulin-secreting cells generated from adult pancreatic acinar cells. Proc. Natl. Acad. Sci. USA 102: 15116-15121.

28. Jenny M, Uhl C, Roche C, Duluc I, Guillermin V, Guillemot F, Jensen J, Kedinger M and Gradwohl $G$ (2002) Neurogenin3 is differentially required for endocrine cell fate specification in the intestinal and gastric epithelium. Embo Journal 21: 6338-6347.

29. Gu GQ, Brown JR and Melton DA (2003) Direct lineage tracing reveals the ontogeny of pancreatic cell fates during mouse embryogenesis. Mechanisms of Development 120: 35-43.

30. Gasa R, Mrejen C, Leachman N, Otten M, Barnes M, Wang JH, Chakrabarti S, Mirmira R and German M (2004) Proendocrine genes coordinate the pancreatic islet differentiation program in vitro. Proceedings of the National Academy of Sciences of the United States of America 101: 13245-13250.

31. Smith SB, Watada H and German MS (2004) Neurogenin3 activates the islet differentiation program while repressing its own expression. Mol. Endocrinol. 18: $142-149$.

32. Rubinson DA, Dillon CP, Kwiatkowski AV, Sievers C, Yang L, Kopinja J, Rooney DL, Ihrig MM, McManus MT, Gertler FB, Scott ML and Van PL (2003) A lentivirus-based system to functionally silence genes in primary mammalian cells, stem cells and transgenic mice by RNA interference. Nat. Genet. 33: 401-406.

33. McManus MT and Sharp PA (2002) Gene silencing in mammals by small interfering RNAs. Nat. Rev. Genet. 3: 737-747.

34. Naldini L (1998) Lentiviruses as gene transfer agents for delivery to non-dividing cells. Current Opinion in Biotechnology 9: 457-463.

35. Rausa F, Samadani U, Ye HG, Lim L, Fletcher CF, Jenkins NA, Copeland NG and Costa RH (1997) The cut-homeodomain transcriptional activator HNF-6 is coexpressed with its target gene HNF-3 beta in the developing murine liver and pancreas. Developmental Biology 192: 228-246.

36. Lahuna O, Rastegar M, Maiter D, Thissen JP, Lemaigre FP and Rousseau GG (2000) Involvement of STAT5 (signal transducer and activator of transcription 5) and HNF-4 (hepatocyte nuclear factor 4) in the transcriptional control of the hnf6 gene by growth hormone. Molecular Endocrinology 14: 285-294.

37. Yuan B, Latek R, Hossbach M, Tuschl T and Lewitter F (2004) siRNA Selection Server: an automated siRNA oligonucleotide prediction server. Nucleic Acids Res. 32: W130-W134.

38. Blume N, Petersen JS, Andersen LC, Kofod H, Dyrberg T and Michelsen BK et al (1992) Immature transformed rat islet beta-cells differentially express Cpeptides derived from the genes coding for insulin I and II as well as transfected human insulin gene. Mol. Endocrinol. 6: 299-307.

39. Eger A, Stockinger A, Schaffhauser B, Beug H and Foisner R (2000) Epithelial mesenchymal transition by c-Fos estrogen receptor activation involves nuclear translocation of beta-catenin and upregulation of beta-catenin/lymphoid enhancer binding factor-1 transcriptional activity. J Cell Biol 148: 173-188.

40. Pierrcux CE, Vanhorenbeeck V, Jacquemin $P$, Lemaigre FP and Rousseau GG (2004) The transcription factor hepatocyte nuclear factor-6/Onecut-1 controls the expression of its paralog Onecut-3 in developing mouse endoderm. J. Biol. Chem. 279: 51298-51304. 